\title{
Effects of material properties and testing parameters on wear properties of fine-grain zirconia (TZP)
}

\author{
Chih-Chung T. Yang, Wen-Cheng J. Wei * \\ Institute of Materials Science and Engineering, National Taiwan University, 1 Roosevelt Rd. Section 4, 106, Taipei, Taiwan
}

Received 9 August 1999; received in revised form 3 April 2000; accepted 18 April 2000

\begin{abstract}
The wear behaviors of yttria-doped tetragonal zirconia polycrystal (Y-TZP) ceramics with different microstructures worn against diamond wheel under various wearing conditions were investigated and compared to that of dense magnesia-doped partially stabilized zirconia (Mg-PSZ) and fine-grain $\mathrm{Al}_{2} \mathrm{O}_{3}$. A block-on-wheel tribometer with unidirectional sliding was used to carry out the wear experiments. The friction coefficient of dry sliding was recorded. The worn surfaces of these materials were also characterized by X-ray diffractometry (XRD), scanning electron microscopy (SEM) and surface profilometry. The wear resistance of worn pieces were analyzed and determined. The possible wear mechanisms and a master wear equation of the ceramics are proposed and discussed. (C) 2000 Published by Elsevier Science S.A.
\end{abstract}

Keywords: Mg-PSZ; Y-TZP; Alumina; Block-on-wheel; Friction coefficient; Wear

\section{Introduction}

Because of inherent covalent bonding, structural ceramics have a high hardness, a good strength at high temperature and resistance to acid or base corrosion. Therefore, they can be used under hostile environments, i.e. high temperature, and still show excellent performance. Due to their unique physical and chemical properties, they are often used as wear-resistant components. Wire-drawing machines, cutting tools, mechanical seals, water faucet valves, pump components, nozzles, ball milling media, automotive components, bearings, and gears are reported before [1].

Wear can be defined as the progressive loss of material due to relative motion between sliding pairs. Basically, it can be divided into two categories: impingement and rubbing wear. Rubbing wear involves two surfaces of sliding pairs brought into contact with or without abrading particles acting as a third-body between the pairs and it occurs as one of the two surfaces is harder than the other one [2]. In this study, we focus on rubbing wear.

\footnotetext{
* Corresponding author.

E-mail address: wjwei@ccms.ntu.edu.tw (W.-C.J. Wei).
}

It was reported [3] that there were several parameters that would affect wear resistance of ceramics. As a matter of fact, wear resistance is a function of material properties, i.e. hardness, strength, fracture toughness, thermal conductivity, thermal expansion, and microstructure. In the field of wear applications, alumina is one of the most commonly used wear-resistant ceramics. Though alumina has a high hardness, the fracture toughness of alumina is lower when compared to zirconia materials including magnesia-doped partially stabilized zirconia (Mg-PSZ) and yttria-doped tetragonal zirconia polycrystal (Y-TZP). As a result, it is expected that ceramic materials with higher fracture toughness can compensate for the lower hardness. Therefore, it is accepted that a ceramic with higher toughness should have a better wear resistance.

Furthermore, it is well known that the wear resistance of ceramics is affected by microstructures such as grain size and porosity $[3,4]$. It was reported that the presence of porosity produced adverse side effects on mechanical properties because the existence of pores causes stress concentration resulting in a decrease in strength and hardness. It is logical to expect that the wear resistance of ceramics will be reduced by residual porosity.

Y-TZP was recently developed to show a small grain size $(0.3-0.4 \mu \mathrm{m})$, high flexural strength (1000-1500 

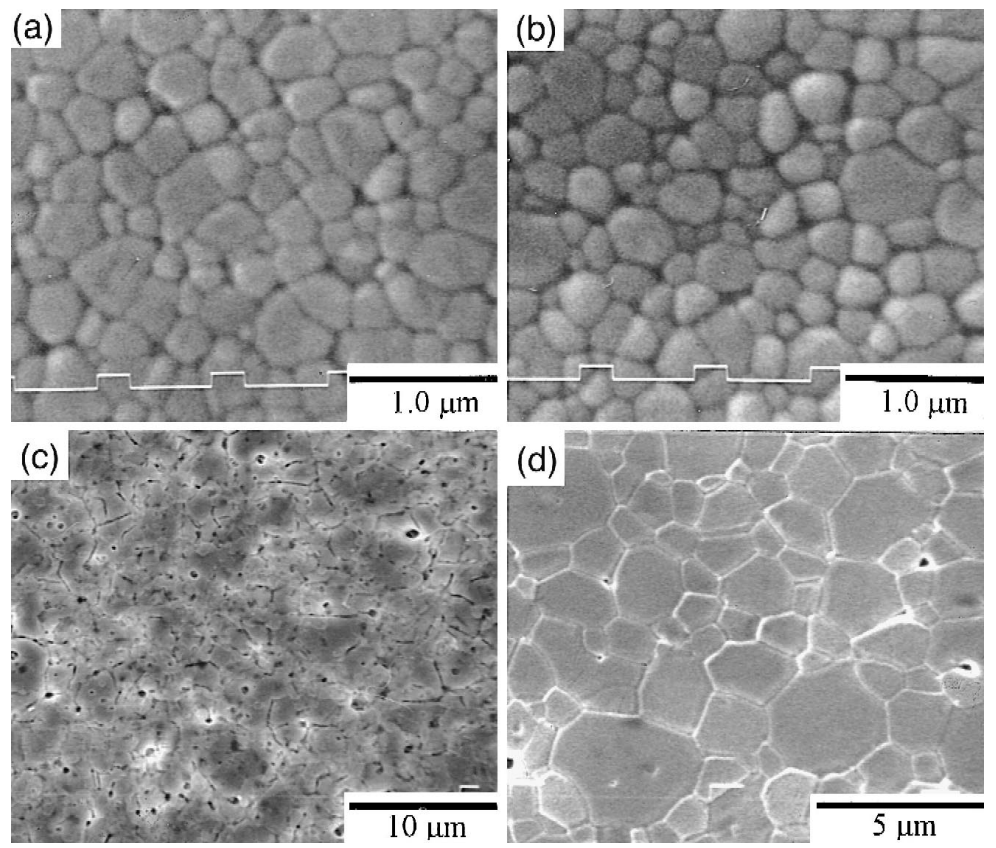

Fig. 1. SEM micrographs of polished and etched (a) TZPCS1 (b) TZPD (c) PSZD and (d) $\mathrm{Al}_{2} \mathrm{O}_{3}$.

$\mathrm{MPa})$ and high fracture toughness $\left(8-10 \mathrm{MPa}^{1 / 2}\right)$ [5]. Y-TZP also shows a high-temperature mechanical properties or low-temperature degradation resistance in water or water vapor environments, especially at $150-400^{\circ} \mathrm{C}$ [6]. Without the occurrence of monoclinic phase, a better wear resistance of the Y-TZP with a high fracture toughness is expected. Therefore, the investigation of wear behavior of Y-TZP as a function of grain size is necessary since the amount of phase transformation caused by grain size effect definitely affects the wear resistance. The objectives of present research are to investigate the influences of material properties and testing parameters (including normal contact load and sliding velocity) on wear properties of the two zirconia materials worn against diamond wheel in the absence of lubricant, and to compare the wear mechanisms between materials. Based on the wear results, a master wear equation is obtained to correlate the dependence of material properties and testing parameters on wear resistance.

\section{Experimental procedure}

The materials used in the present investigation were as follows: (i) $3 \mathrm{~mol} \%$ Y-TZP either prepared by colloidal processing or die-pressing (TZPC or TZPD); (ii) $3.5 \mathrm{wt} \%$ magnesia-partially-stabilized zirconia prepared by diepressing (PSZD). The detailed processing conditions were reported elsewhere [7]; (iii) dense and fine-grained $\mathrm{Al}_{2} \mathrm{O}_{3}$. Wang [8] reported that the $\mathrm{Al}_{2} \mathrm{O}_{3}$ has a four-point flexural strength of $450 \mathrm{MPa}$ and Vickers' hardness of $16.8 \mathrm{GPa}$. The average grain size is $3.2 \mu \mathrm{m}$. The density of alumina was $3.95 \mathrm{~g} / \mathrm{cm}^{3}$ and showed a porosity of $0.9 \pm 0.1 \%$. Fig. 1 shows the microstructures of these four materials.

The wear resistance and friction coefficient of zirconia and alumina ceramics were determined in controlled environment using a block-on-wheel apparatus (Multi-Purpose Friction and Wear Tester, TE53/7891, Plint \& Partners, England). The diamond wheel with a grit size 800 mesh was mounted on the tester and used as a wheel. It was also dressed every 4000 counts. ${ }^{1}$ The ceramic specimen machined into the form of plates with dimensions $12.7 \mathrm{~mm} \times$ $3.0 \mathrm{~mm} \times 4.0 \mathrm{~mm}$ was used as a sample block. The wear tests were performed inside a chamber with a relative humidity $67 \pm 2 \%$. The applied normal loads were from 42 to $242 \mathrm{~N}$ corresponding to the contact pressure of either 1.0 or $6.4 \mathrm{MPa}$, respectively. The sliding velocities were from 0.63 to $1.89 \mathrm{~m} / \mathrm{s}$. The tangential friction force was simultaneously recorded with a load cell.

The grain size of the sample was determined from the SEM micrographs by line intercept technique [9]. More than 200 grains were counted on micrographs. The fourpoint flexural strength measurement was performed by a material testing system (MTS 810, MTS, USA) and followed ASTM F417-78. The single-edge-notched-beam [10] was adopted to determine the fracture toughness by a material testing system same as flexural strength measurement. The wear rate of the ceramic specimen was calculated by measuring mass loss with an electrical microbal-

\footnotetext{
${ }^{1}$ Please refer the data shown in Fig. 2 which depicts the measurements of the mass loss under various surface conditions of the diamond wheel.
} 
Table 1

Wear properties of TZPC worn against 800 mesh diamond wheel under $0.63 \mathrm{~m} / \mathrm{s}$ and $42 \mathrm{~N}$

\begin{tabular}{lllclc}
\hline Sample & $\begin{array}{l}\text { Grain size } \\
(\mu \mathrm{m})\end{array}$ & $\begin{array}{l}\text { Wear rate } \\
\left(\times 10^{-8}, \mathrm{~cm}^{3} / \mathrm{Nm}\right)\end{array}$ & \multicolumn{2}{c}{ Monoclinic phase $(\%)$} & $\begin{array}{l}\text { Surface roughness } \\
R_{\mathrm{a}}(\mu \mathrm{m})\end{array}$ \\
\hline TZPCS1 & 0.40 & 3.98 & As-annealed & Worn surface & 0.42 \\
TZPCS2 & 0.45 & 4.03 & 0 & 0 & 0.44 \\
TZPCS3 & 0.60 & 4.20 & 0 & 0 & 0.44 \\
TZPCS4 & 0.70 & 6.02 & 0 & 3.0 & 0.46 \\
TZPCS6 & 0.81 & 6.45 & 11.8 & 5.6 & 0.50 \\
TZPCS8 & 1.20 & 8.00 & 13.9 & 8.5 & 0.48 \\
\hline
\end{tabular}

ance. The phase transformation of Y-TZP and Mg-PSZ was determined by an X-ray diffractometer (XRD) using $\mathrm{Cu} \mathrm{K}{ }_{\alpha}$ radiation (PW 1792, Philips Instrument, Netherlands). The morphologies of wear tracks were examined using scanning electron microscopy (SEM, JSM-T100, JEOL, Japan). The surface roughness was measured by a surface profilometer (Surfcorder SE-2300, Kosaka Lab., Tokyo, Japan).

\section{Results and discussion}

\subsection{Grain size effects of $Y$-TZP}

The grain size and the amount of $\mathrm{m}$-phase of the TZPC sintered at $1480^{\circ} \mathrm{C}$ for 1 to $8 \mathrm{~h}$ are listed in Table 1 . The wear properties of the TZPCS1 at an applied normal load of $42 \mathrm{~N}$ and a sliding velocity of $0.63 \mathrm{~m} / \mathrm{s}$ are also listed in Table 1, which shows the wear resistance of TZPC decreases with increasing grain size and $\mathrm{m}$-phase content. The wear rate of TZPCS8 (sintered at $1480^{\circ} \mathrm{C}$ for $8 \mathrm{~h}$ ) is about two times of that of TZPCS1 (sintered at $1480^{\circ} \mathrm{C}$ for $1 \mathrm{~h})$. However, there is no significant difference between surface roughness. The $R_{\mathrm{a}}$ of those TZPC samples is in the range of $0.42-0.50 \mu \mathrm{m}$.

The wear resistance and the amount of m-phase as a function of grain size is plotted in Fig. 3. The critical grain size of as-annealed TZPC for $\mathrm{t}$ - to $\mathrm{m}$-phase transformation is between 0.5 and $0.7 \mu \mathrm{m}$. When sintered at $1480^{\circ} \mathrm{C}$ longer than $6 \mathrm{~h}$, the m-phase content on the surfaces increases from $0 \%$ to $11.8 \%$, showing the occurrence of spontaneous t- to $\mathrm{m}$-phase transformation on sample surface. He et al. [4] reported that the critical grain size for sliding wear of a $\mathrm{SiC}$ ball on a TZP plate is in the range of average grain size $0.5-0.7 \mu \mathrm{m}$.

As depicted in Fig. 3, the wear resistance as a function of grain size can be divided into two regions and expressed in the form [11]

$R=k \times G^{-n}$

where $k$ is a constant, $G$ is the average grain size. It is shown in the figure that there are two values of $n$ that are obtained. For fine-grain samples, the values of $n_{1}$ equals 0.5 ; however, the value of $n_{2}$ is 1.0 for large-grain sam- ples. For region I, the wear resistance versus grain size can be described by Hall-Petch-type relationship [12]. It is found that the transition of $n$ from 0.5 to 1.0 coincides with the t- to m-phase transformation, which is induced during unidirectional sliding once the grain size exceeds the critical value, as indicated in Table 1 . This means that the phase transformation due to the larger grain size starts to play a role in material removal mechanism, therefore accelerating the wear rate. The value of $n$ is consistent with other researchers' results $[11,13,14]$.

Fig. 4(a) and (b) shows the morphologies of the worn surfaces of two tested samples. Because of similar wear tracks, only the typical morphologies of TZPCS1 and TZPCS6 are shown to compare the wear results. The surfaces of samples all show similar plastic deformation with redeposition of wear debris. Basically, wear debris redeposition can be done by van der Waals force, which is always attractive [15]. The film transfer (wear debris reattachment) can be continuous or islandized. Also, the wear particles can be deposited into surface pits caused by severe wear. Usually, these trapped debris particles on the

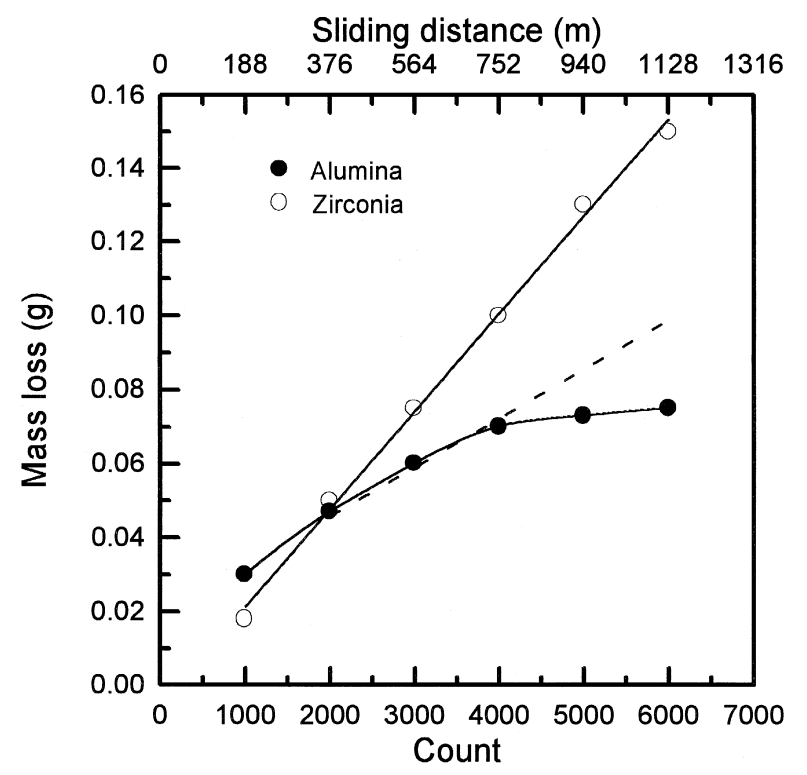

Fig. 2. Mass loss of $\mathrm{ZrO}_{2}$ and $\mathrm{A}_{2} \mathrm{O}_{3}$ against sliding distance, showing the how diamond wheel should be dressed after 4000 counts. 


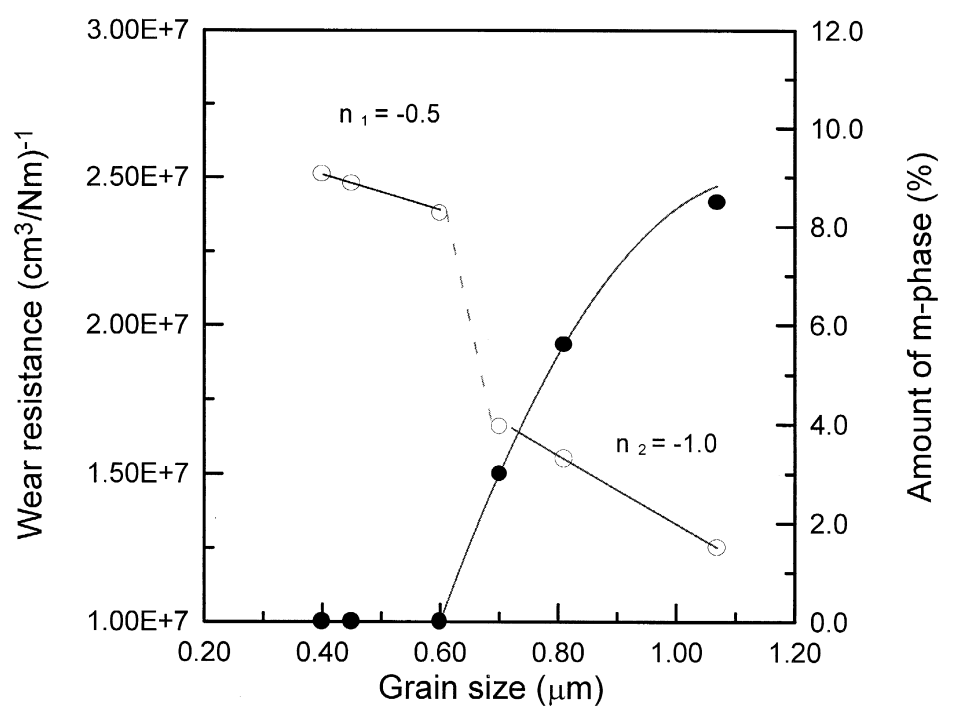

Fig. 3. The wear resistance and amount of $\mathrm{m}$-phase of various TZPC as a function of grain size. The wear conditions were performed at a sliding velocity of $0.63 \mathrm{~m} / \mathrm{s}$ and an applied normal load of $42 \mathrm{~N}$.

sample surface will undergo further fragmentation and microyielding with increasing sliding distance when those small fragments appear in the surface pits.

\subsection{The influence of testing parameters}

Fig. 5 shows the relationship of the mass loss of TZPCS1 and applied normal load at a sliding velocity of

(a)

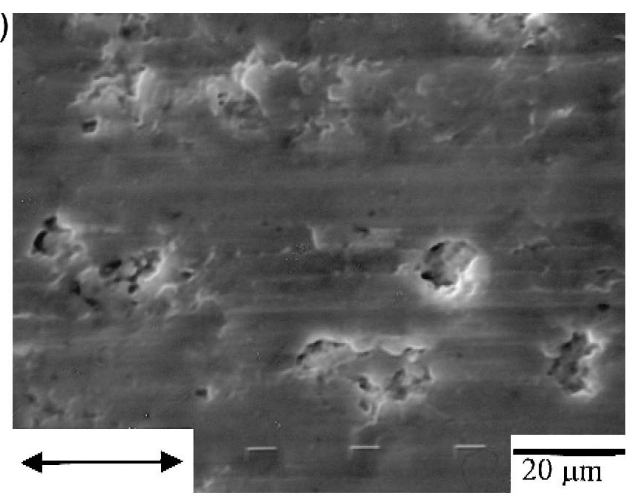

(b)

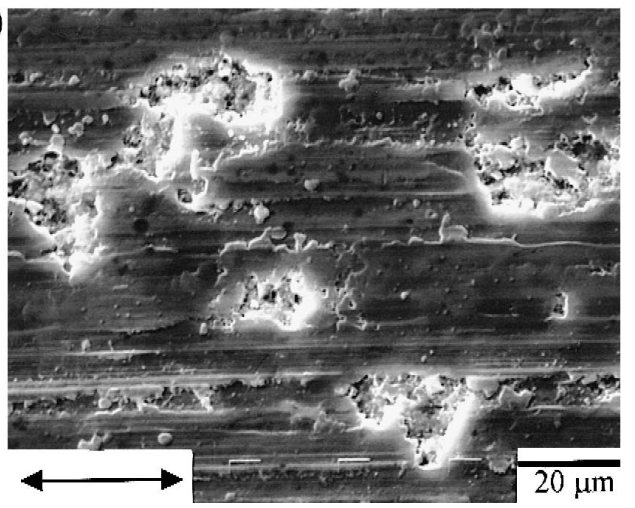

Fig. 4. SEM micrographs of the worn morphologies of (a) TZPCS1 tested at $0.63 \mathrm{~m} / \mathrm{s}$ and $42 \mathrm{~N}$ and (b) TZPCS6 tested at $0.63 \mathrm{~m} / \mathrm{s}$ and $42 \mathrm{~N}$.
$0.63 \mathrm{~m} / \mathrm{s}$. The mass loss increases slowly with increasing applied normal load up to $142 \mathrm{~N}$. However, the mass loss increases dramatically at an applied normal load greater than $142 \mathrm{~N}$, implying a change of wear mechanism from mild deformation (Fig. 4(a)) to a severe brittle fracturing mode (Fig. 6). The morphologies of worn surface of TZPCS1 at an applied normal load of $192 \mathrm{~N}$ is shown in Fig. 6. In addition to the deformation, micro-fracturing and wear debris reattachment are formed and observed. The worn morphologies are different from those tested at lower applied normal load $(<145 \mathrm{~N})$.

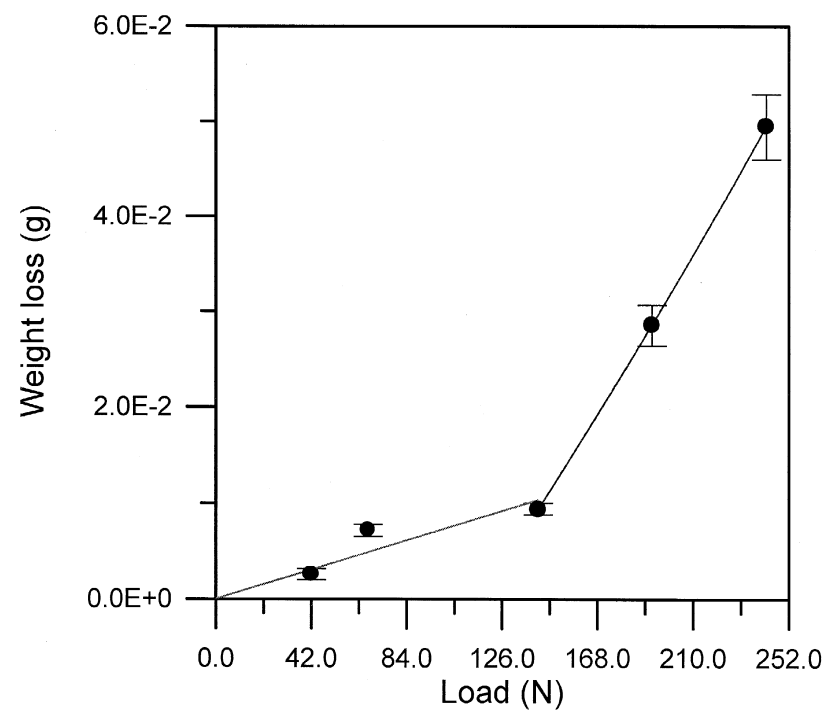

Fig. 5. The relationship of mass loss of TZPCS1 and applied normal load at a sliding velocity of $0.63 \mathrm{~m} / \mathrm{s}$ testing condition. The sliding distance for each wear condition is $377 \mathrm{~m}$. The wear mechanism changes from mild plastic deformation to a brittle fracturing mode at an applied normal load greater than $142 \mathrm{~N}$. 


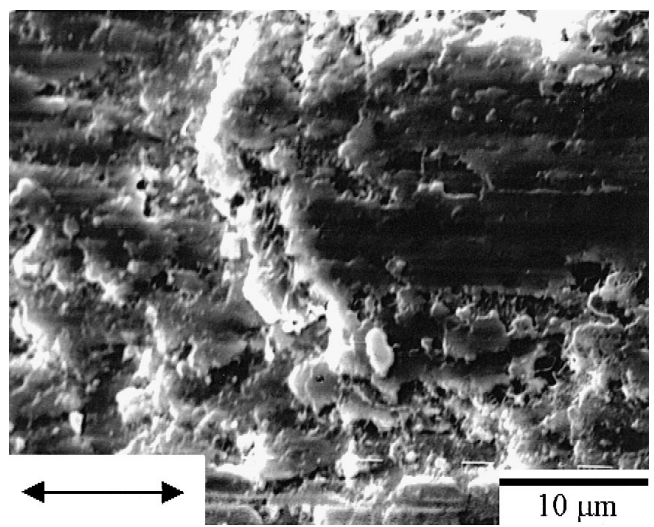

Fig. 6. SEM micrograph of the worn surface of TZPCS1 tested at an applied normal load of $192 \mathrm{~N}$ and a sliding velocity of $0.63 \mathrm{~m} / \mathrm{s}$.

The relationship of mass loss and sliding velocity at a given normal applied load of $42 \mathrm{~N}$ is shown in Fig. 7 . Initially, the mass loss at the same testing distance increases with sliding velocity significantly and linearly up to a sliding velocity of $1.26 \mathrm{~m} / \mathrm{s}$ and then reaches a stable value. The mass loss remains almost constant at a sliding velocity higher than $1.26 \mathrm{~m} / \mathrm{s}$. The change of the mass loss per distance implies the change of wear mechanism. The morphologies of worn surfaces at a sliding velocity of $1.57 \mathrm{~m} / \mathrm{s}$ is shown in Fig. 8. The plastic deformation at mild material removing rate disappears. Instead, the worn surface (Fig. 8) exists in the form of severe brittle fracture plus minor plastic deformation. Based on the above results shown in Figs. 4-7, we choose 42 or $67 \mathrm{~N}, 0.63$ or 1.57 $\mathrm{m} / \mathrm{s}$ as two wear testing parameters to investigate the wear performances of TZPC, TZPD and PSZD in order to obtain the details of material removal mechanism.

The average grain size, fracture toughness and four-point flexural strength of the samples are listed in Table 2. As

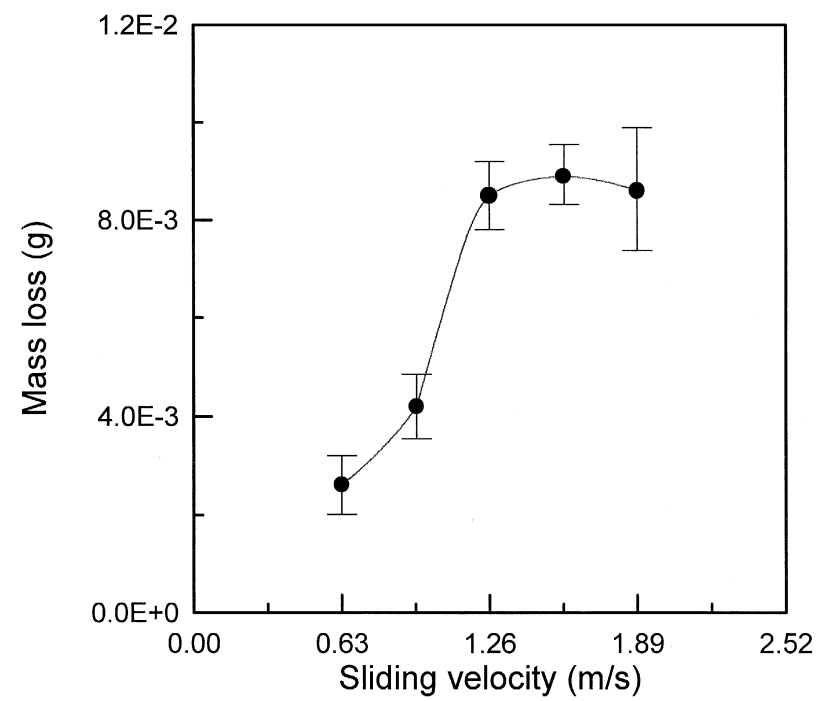

Fig. 7. The relationship of mass loss of TZPCS1 and sliding velocity at an applied normal load of $42 \mathrm{~N}$. The sliding distance for each wear condition is $377 \mathrm{~m}$. The wear mechanism changes to a brittle fracturing mode as the sliding velocity is higher than $1.26 \mathrm{~m} / \mathrm{s}$.

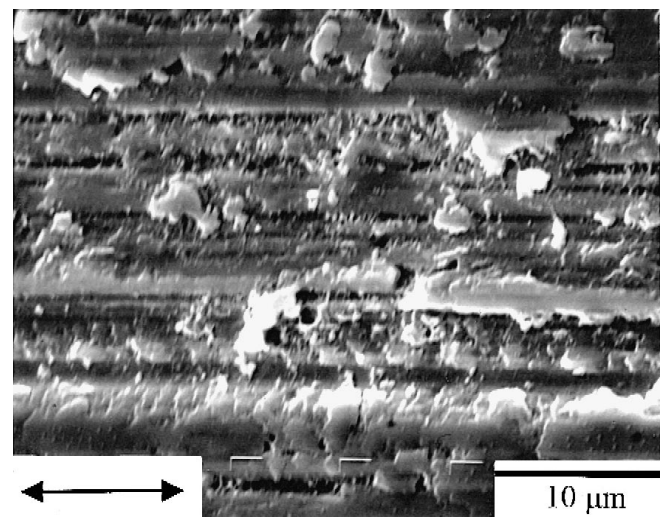

Fig. 8. The morphologies of the worn surfaces of TZPCS1 at a sliding velocity of $1.57 \mathrm{~m} / \mathrm{s}$ and an applied normal load of $42 \mathrm{~N}$.

indicated in Table 2, the grain size of TZPCS1 and TZPD is 0.40 and $0.42 \mu \mathrm{m}$, respectively; however, the grain size of PSZD is $12.0 \mu \mathrm{m}$. The TZPCS1 has the highest fracture toughness (9.8 $\mathrm{MPa} \mathrm{m}^{1 / 2}$ ) and flexural strength (723 $\mathrm{MPa})$. The wear properties of the tested samples at an applied normal load of either 42 or $67 \mathrm{~N}$ are also listed in Table 2. The wear rate of three $\mathrm{ZrO}_{2}$ materials increases with increasing applied normal load and sliding velocity, as indicated in Tables 1 and 2, but TZP materials are still better than PSZD in terms of wear resistance. Fig. 9(a) and (b) shows the changes of friction coefficient of individual $\mathrm{ZrO}_{2}$ materials. Though the wear rate of all samples remains almost constant with increasing sliding distance, the friction coefficient shows a different behavior. For TZP either prepared by colloidal processing or die-pressing, the friction coefficient decreases slightly with increasing sliding distance. But the friction coefficient of PSZD after 4000 revolutions increases or decreases depending greatly on the dressing condition of the diamond wheel, as shown in Fig. 9.

It is believed that a higher tangential force should cause a higher wear rate from the viewpoint of energy input. Under the cases being studied, the friction coefficient of PSZD is about $15 \%$ higher than that of TZPCS1. But the wear rate of PSZD is about eight times higher than TZPCS1, implying that the tangential force is partially responsible for the material removal under the same testing conditions. Since the testing parameters are controlled, the material properties should play an important role in the wear resistance of materials. For PSZD, the higher wear rate is obtained due to a lower fracture toughness, larger grain size and a little lower hardness when compared to TZPCS1.

\subsection{The wear comparison between TZPCS1 and $\mathrm{Al}_{2} \mathrm{O}_{3}$}

Fig. 10 shows the wear rate of TZPCS1 and $\mathrm{Al}_{2} \mathrm{O}_{3}$. It can be seen that the wear rate of $\mathrm{Al}_{2} \mathrm{O}_{3}$ is 8.3 times higher than that of TZPCS1. In other words, the wear resistance of TZPCS1 is better than that of $\mathrm{Al}_{2} \mathrm{O}_{3}$. The friction 
Table 2

Wear properties of $\mathrm{ZrO}_{2}$ worn against diamond wheel under two different wear conditions

\begin{tabular}{|c|c|c|c|c|c|c|c|c|}
\hline \multirow[t]{2}{*}{ Sample } & \multirow{2}{*}{$\begin{array}{l}\text { Grain size } \\
(\mu \mathrm{m})\end{array}$} & \multirow{2}{*}{$\begin{array}{l}K_{\mathrm{IC}} \\
\left(\mathrm{MPa} \mathrm{m}^{1 / 2}\right)\end{array}$} & \multirow{2}{*}{$\begin{array}{l}\sigma_{4 \mathrm{p}} \\
(\mathrm{MPa})\end{array}$} & \multirow{2}{*}{$\begin{array}{l}H_{\mathrm{v}} \\
(\mathrm{GPa})\end{array}$} & \multicolumn{2}{|c|}{ Wear rate $\left(\times 10^{-8}, \mathrm{~cm}^{3} / \mathrm{N} \mathrm{m}\right)$} & \multicolumn{2}{|c|}{ Monoclinic phase (\%) } \\
\hline & & & & & $42 \mathrm{~N}, 1.57 \mathrm{~m} / \mathrm{s}$ & $67 \mathrm{~N}, 0.63 \mathrm{~m} / \mathrm{s}$ & As-annealed & Worn surface \\
\hline TZPCS1 & 0.40 & $9.8 \pm 1.3$ & 723 & 12.4 & 18.0 & 4.74 & 0 & 1.0 \\
\hline TZPD & 0.42 & $7.6 \pm 1.0$ & 545 & 12.4 & 17.1 & 6.04 & 0 & 3.9 \\
\hline
\end{tabular}

coefficient of $\mathrm{Al}_{2} \mathrm{O}_{3}$ is in the range of $0.58-0.62$ and the changes of the friction coefficient is similar to the results shown in Fig. 9. The worn morphologies of $\mathrm{Al}_{2} \mathrm{O}_{3}$ sample are shown in Fig. 11. The wear mechanism is different when compared to TZPCS1 (Fig. 3(a)). For $\mathrm{Al}_{2} \mathrm{O}_{3}$, the mechanism for materials removal is micro-fracturing with a little amount of grain pull-out, which is a typical result of transgranular fracture that occurs on ceramic surface. As indicated in Fig. 11, the flaw size is about $20 \mu \mathrm{m}$, which is six times larger than the average grain size of $\mathrm{Al}_{2} \mathrm{O}_{3}$.

\subsection{The relationship between material properties and wear rate}

The dependence of material properties and testing parameters on the wear resistance is very complicated. In this
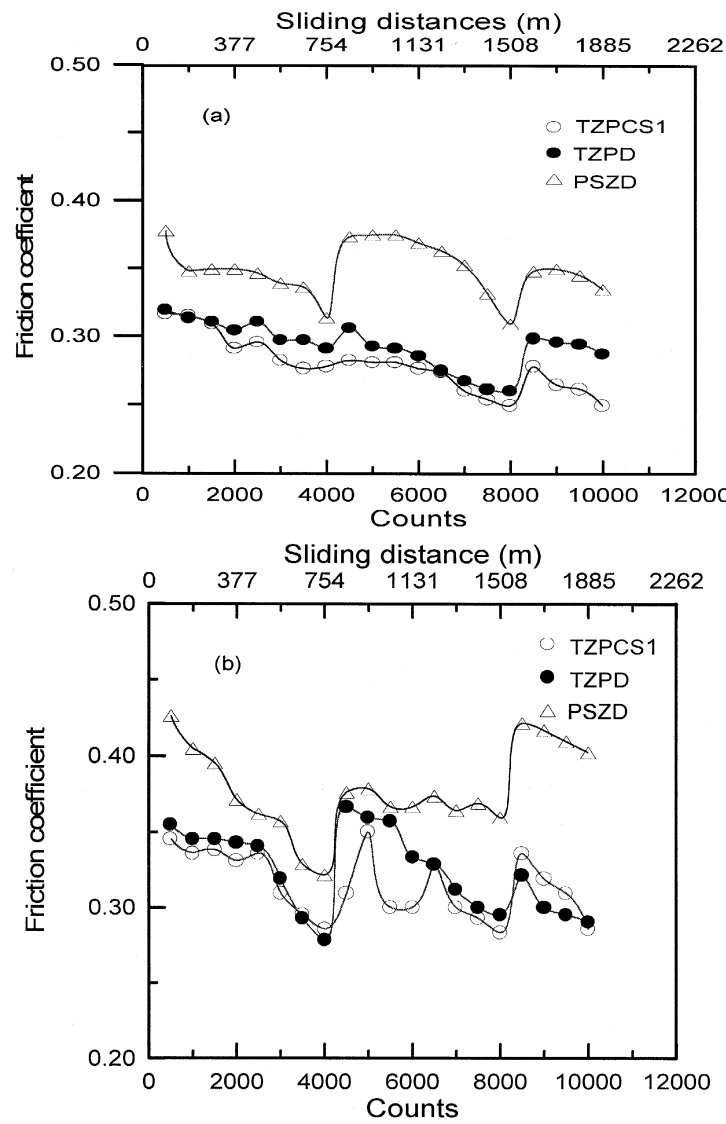

Fig. 9. The friction coefficient of zirconia materials (a) at a sliding velocity of $0.63 \mathrm{~m} / \mathrm{s}$ and an applied normal load of $67 \mathrm{~N}$ and (b) at a sliding velocity of $1.57 \mathrm{~m} / \mathrm{s}$ and an applied normal load of $42 \mathrm{~N}$. research, it is attempted to correlate the relationship between material properties, such as grain size (microstructure), fracture toughness, hardness, etc. and testing parameters to the wear behavior. Evans and Marshall [16] proposed an equation to describe the removed volume as:

$V=\alpha \frac{P^{9 / 8}}{K_{\mathrm{c}}^{1 / 2} H^{5 / 8}}(E / H)^{4 / 5}$

where $V$ is the wear rate, $\alpha$ is a material-independent constant, $P$ is the normal load, $K_{\mathrm{c}}$ is the toughness, $H$ is the hardness and $E$ is the Young's modulus of ceramics materials. Fig. 12 shows the dependence of material properties on wear rate. According to Eq. (2), the fitting line in the figure implies that the wear rate can be described in terms of material properties under the same testing parameters. The higher fracture toughness and hardness, the lower the wear rate. Besides, the wear rate increases with increasing grain size $(G)$ for TZPCS1, TZPD and PSZD.

The results of this research show that the wear rate is a function of grain size and in combination with Eq. (2):

$R_{\mathrm{w}}=\frac{W}{P \times L}=k G^{1 / 2} K_{\mathrm{IC}}^{-1 / 2} H_{\mathrm{v}}^{-5 / 8}(N / H)^{4 / 5}$

where $W$ is mass loss, $P$ is the applied load, $L$ is the sliding distance, $k$ is a constant, $G$ is the average grain size, $K_{\text {Ic }}$ is the fracture toughness in mode $\mathrm{I}$, and $H_{\mathrm{v}}$ is the Vickers' hardness. From the wear results obtained in this research, it seems that Eq. (3) only can apply for grain size less than $0.6 \mu \mathrm{m}$ for TZPC and TZPD. However, it is

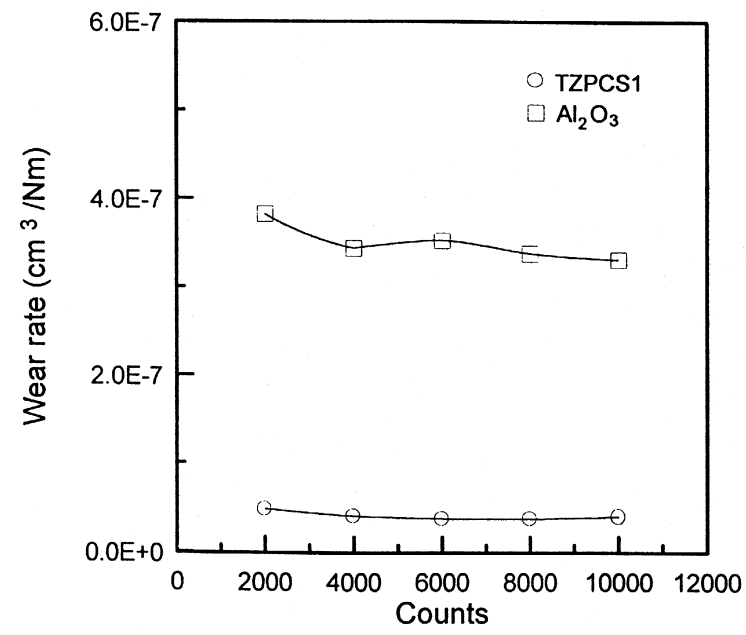

Fig. 10. The comparison of $\mathrm{Al}_{2} \mathrm{O}_{3}$ and TZPCS1 at a sliding velocity of $0.63 \mathrm{~m} / \mathrm{s}$ and an applied normal load of $42 \mathrm{~N}$. 


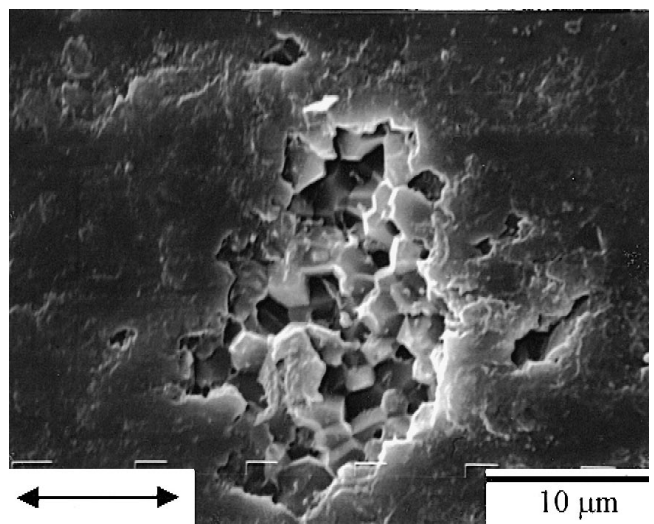

Fig. 11. The morphologies of the worn surfaces of $\mathrm{Al}_{2} \mathrm{O}_{3}$, showing the grain pull-out.

found in the present study that the dependence of grain size of $\mathrm{Al}_{2} \mathrm{O}_{3}$ and PSZD also follows the relationship of TZPC and TZPD. Therefore, a linear fitting line can be obtained to correlate the dependence of material properties and testing parameters on the wear resistance of tested materials. The dependence of grain size $(n=1)$ on TZPCS4-8 is also shown in Fig. 12 to compare with the result of TZPCS1. Obviously, it shows a different grain size effect on wear rate as the value of $n$ changes from 0.5 to 1.0. Under the cases being studied, grain size is just one of the competing wear factors responsible for the material removal rate. Other factors such as fracture toughness, hardness and Young's modulus affecting the wear resistance of the tested materials should be considered at the same time. TZP with higher fracture toughness and smaller grain size can compensate its lower hardness; therefore, the wear resistance can be improved.

Two sequential and consequential processes take place in ductile materials when the diamond grits (abrasive particles) contact and slide against the surface of a ductile material. One is the formation of a series of parallel grooves that do not cause direct material removal. The other is the detachment of materials in the form of discontinuous microchips, leading to the direct material removal. Moreover, plastic deformation is not only confined to the grooves, instead there exists an extensive plastic zone beneath the worn surface. In the case of ductile materials ground by diamond grits or abrasives, materials are deformed to the sides of the grooves and wear off in the form of minor microchips. The removed volume per unit area per unit sliding distance can be expressed as [17]:

$W=K_{1} \times K_{2} \times K_{3} \times \sigma \times H^{1}$

where $K_{1}$ is the probability of wear debris formation, $K_{2}$ is the mean proportion of groove volume, $K_{3}$ is a constant depending on the shape of the particles, $\sigma$ is the contact stress and $H$ is the hardness of the tested material. It is clear that material removal increases with increasing applied load or decreasing the hardness.
However, in the case of brittle material, material is removed by the extension of lateral crack when they intersect each other and/or propagate to the surface. Though Eq. (3) assumes a lateral crack mechanism, it does not mean that the Eq. (3) only applies to the higher velocity range. The lateral fracture model assumes the existence of plastic zone with the occurrences of radial, lateral and median cracks as the brittle material is indented. As the material is subjected to either low or high external forces (or either low or high sliding velocity), it is possible that some of the localized stress intensity of the tested materials may exceed the critical stress intensity [18] and then microcracks may start to nucleate and propagate. When these lateral microcracks propagate to the surface of the tested materials, the material removal takes place. It is believed that microcracks can be nucleated in a plastic zone by: (1) t- to m-transformation, (2) twinning, (3) grain sliding and (4) strain incompatibility. It is the local deformation that leads to the nucleation of these microcracks by one of the nucleation processes in deformed region mentioned above, and then to the propagation of microcracks to the surfaces of the tested materials. When the potential chipping zones come off the material, the wear debris redeposited on the sample surface will undergo further fragmentation and microyielding as the sliding distances increase. Therefore, in addition to brittle fracture, one can observe the microplastic and smooth worn surfaces with the occurrences of surface pits. In other words, it is the extension of lateral crack, leading to the material removal and redeposition of wear debris, leading to the smooth worn surfaces. Therefore, the master equation proposed in

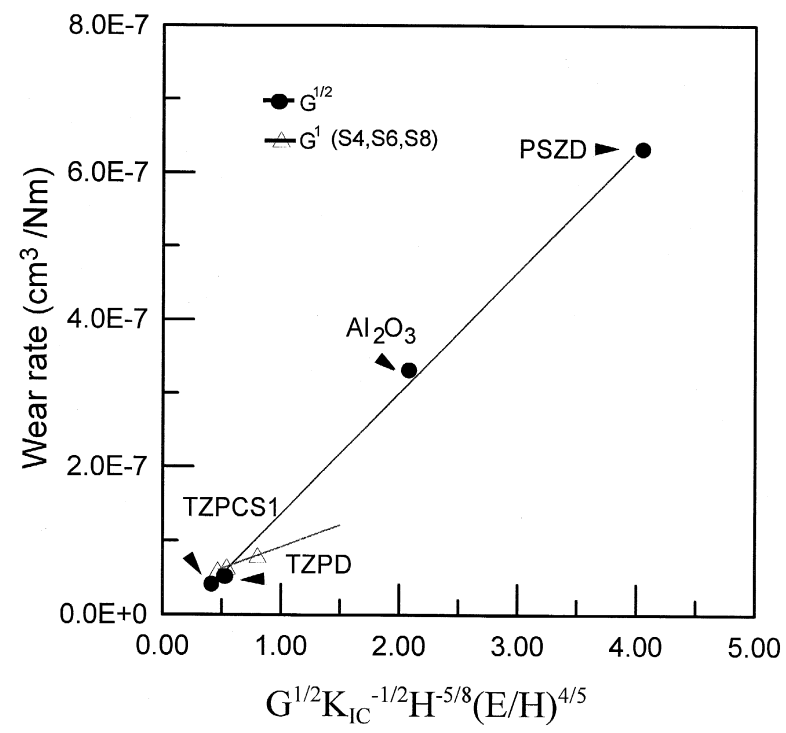

Fig. 12. The relationship between wear rate and material properties tested in this system. The wear tests were performed at a sliding velocity of 0.63 $\mathrm{m} / \mathrm{s}$ and an applied normal load of $42 \mathrm{~N}$. Note the results of TZPCS4-8 are plotted in the condition of $G^{1,0}$. 
this research is suitable for the brittle-mode wear mechanism with smooth surfaces.

\section{Conclusion}

Based on the wear experiments, micro-crack formation due to t- to m-phase transformation and wear debris re-deposition resulting from extension of lateral crack are the two major wear mechanisms for contact wearing of $\mathrm{ZrO}_{2}$ materials. Grain pull-out is the other one for the $\mathrm{Al}_{2} \mathrm{O}_{3}$ sample. The following are the conclusions obtained.

(1) The wear resistance of TZPC decreases with increasing grain size and weight loss can be expressed in the form of $R=n \times G^{-n}$ (where $G$ is the average grain size). The value of $n=0.5$ for fine-grain samples and $n=1.0$ for large-grain samples is obtained, respectively. The wear resistance of TZPC sintered at $1480^{\circ} \mathrm{C}$ for $1 \mathrm{~h}$ is two times of that of samples sintered at $1480^{\circ} \mathrm{C}$ for $8 \mathrm{~h}$.

(2) The testing parameters influence the wear performance of $\mathrm{ZrO}_{2}$ materials. The wear mechanism changes from plastic deformation with debris transferred to severe brittle fracture at an applied normal of $192 \mathrm{~N}$. There is a turning point of applied contact load $(\leqq 142 \mathrm{~N})$ corresponding to the changes of wear mechanism. Moreover, the sliding velocity affects the wear behavior. The wear mechanism changes from mild plastic deformation to severe brittle fracture at a fast sliding velocity, i.e. $\geq 1.26$ $\mathrm{m} / \mathrm{s}$.

(3) The wear rate of $\mathrm{Al}_{2} \mathrm{O}_{3}$ is 8.3 times higher than that of TZPCS1. The morphologies of worn surfaces of $\mathrm{Al}_{2} \mathrm{O}_{3}$ show micro-fracturing with a little amount of grain pull-out, implying that the wear mechanism of $\mathrm{Al}_{2} \mathrm{O}_{3}$ is different from that of TZPCS1.

(4) A master equation used to correlate the dependence of material properties and testing parameters on the wear resistance of tested materials is proposed. The wear rate is proportional to $G^{n} K_{\mathrm{Ic}}^{-1 / 2} H_{v}^{-1 / 8}(E / H)^{4 / 5}$ where $G$ is the average grain size ( $n$ is 0.5 or 1.0 ), $K_{\text {IC }}$ is the fracture toughness, $H_{\mathrm{v}}$ is the Vickers' hardness and $E$ is the Young's modulus of ceramics. Zirconia materials with higher fracture toughness and smaller grain size can compensate its lower hardness. Hence, it is concluded that high wear resistance of TZPCS1 and TZPD is attributed to the smaller grain size, higher fracture toughness when compared to PSZD and $\mathrm{Al}_{2} \mathrm{O}_{3}$.

\section{Acknowledgements}

The authors would like to thank the National Science Foundation for the financial support under the NSC872622-E-002-014.

\section{References}

[1] T.E. Fischer, Friction and wear of ceramics, Scr. Metall. 24 (1990) 833-838.

[2] D.H. Buckley, Tribological Properties of Structural Ceramics, in Treatise on Materials Science and Technology, Edited by J.B. Wachtman, Jr., 29 293-365.

[3] E. HinesJr, R.C. Bradt, J.V. Biggers, Grain size and porosity effects on the abrasive wear of alumina, in: W.A. Glaeser, K.C. Ludema, S.K. Rhee (Eds.), Wear of Materials, 1977, pp. 462-467.

[4] Y. He, L. Winnubst, A.J. Burggraaf, H. Verweij, Influence of porosity on friction and wear of tetragonal zirconia polycrystal, J. Am. Ceram. Soc. 80 (1997) 377-380.

[5] R.H. Hannink, M.V. Swain, Progress in transformation toughening of ceramics, Annu. Rev. Mater. Sci. 24 (1994) 359-408.

[6] M. Yoshimura, T. Noma, Role of $\mathrm{H}_{2} \mathrm{O}$ on the degradation process of Y-TZP, J. Mater. Sci. Lett. 6 (1987) 455-467.

[7] C.C. Yang, Master thesis, National Taiwan University, (1999).

[8] B.C. Wang, Master thesis, National Taiwan University, (1999).

[9] M.I. Mendelson, Average grain size in polycrystalline ceramics, J. Am. Ceram. Soc. 52 (1969) 443-446.

[10] H. Nisitani, K. Mori, Influence of supporting conditions on stress intensity factors for single-edge-cracked specimens under bending, Tech. Reports Kyushu Univ. 58 (1985) 751-755.

[11] Y. He, L. Winnubst, A.J. Burggraaf, H. Verweij, Influence of porosity on friction and wear of tetragonal zirconia polycrysta, J. Am. Ceram. Soc. 80 (1997) 377-380.

[12] C.C. Wu, R.W. Rice, D. Johnson, b.A. Platt, Grain size dependence of wear in ceramics, Ceram. Eng. Sci. Proc. 6 (1985) 995-1011.

[13] Y. He, L. Winnubst, A.J. Burggraaf, H. Verweij, Grain-size dependence of sliding wear in tetragonal zirconia polycrystals, J. Am. Ceram. Soc. 79 (1996) 3090-3096.

[14] K.H. Zum Gahr, W. Bundschuh, B. Zimmerlin, Effect of grain size on friction and sliding wear of oxide ceramics, Wear 162-164 (1993) 269-279.

[15] O.O. Ajayi, K.C. Ludema, Mechanism of transfer film formation during repeat pass sliding of ceramic materials, Wear 140 (1990) 191-206.

[16] A.G. Evans, D.B. Marshall, Wear mechanisms in ceramics, Fundam. Friction Wear Mater. ASM (1980) 439-452.

[17] M.A. Moore, Abrasive wear, in: D.A. Rigney (Ed.), Fundamentals of Friction and Wear of Materials, 1981, pp. 73-118.

[18] B.R. Lawn, Indentation of ceramics with sphere: a century after Hertz, J. Am. Ceram. Soc. 81 (1998) 1977-1994. 